$$
\text { CONF-960401--59 }
$$

\title{
Correlation of Magnetic Dichroism in X-Ray Absorption and Photoelectron Emission Using Ultrathin Magnetic Alloy Films
}

J.G. Tobin

K.W. Goodman

G.J. Mankey

R.F. Willis

J.D. Denlinger

E. Rotenberg

RECENV:

A. Warwick

JUL 08 isis

$0 \leq 1:$

This paper was prepared for submittal to the 1996 Materials Research Society Spring Meeting

San Francisco, CA

April 8-12, 1996

April 1996

This is a preprint of a paper intended for publication in a journal or proceedings. Since changes may be made before publication, this preprint is made available with the understanding that it will not be cited or reproduced without the permission of the author. 


\section{DISCLAIMER}

This document was prepared as an account of work sponsored by an agency of the United States Government. Neither the United States Government nor the University of California nor any of their employees, makes any warranty, express or implied, or assumes any legal liability or responsibility for the accuracy, completeness, or usefulness of any information, apparatus, product, or process disclosed, or represents that its use would notinfringeprivately owned rights. Reference herein to any specific commercial prodacts, process, or service by trade name, trademark, manufacturer, or otherwise, does not necessarily constitute or imply its endorsement, recommendation, or favoring by the United States Government or the University of Califormia. The views and opinions of authors expressed herein do not necessarily state or reflect those of the United States Government or the Uiniversity of California, and shall not be used for advertising or product endorsement parposes. 


\title{
CORRELATION OF MAGNETIC DICHROISM IN X-RAY ABSORPTION AND PHOTOELECTRON EMISSION USING ULTRATHIN MAGNETIC ALLOY FLMS
}

\author{
J.G. Tobin", K.W. Goodman*, G.J. Mankey"*, R.F. Whilis**, \\ J.D. Denlinger***, E. Rotenberg ${ }^{* * *}$, and A. Warwick \\ * Lawrence Livermore National Laboratory \\ Chemistry and Materials Science Directorate \\ Livermore, CA \\ **Pennsyivania State University \\ Department of Physics \\ University Park, PA \\ ***Lawrence Berkeley Laboratory \\ Adranced Light Scurce \\ Berkeley, CA
}

\begin{abstract}
We have begun a program to characterize magnetic alloy overiayers using both magnetic $x$-ray circular dichroism (MXCD) and magnetic $x$-ray linear dichroism (MXLD). This will allow a direct comparison of MXCD-absorption and MXID-photoelectron emission. First results from the Advanced Light Source will be presented.
\end{abstract}

\section{INTRODUCTION}

Magnetic dichroism techniques based upon the spectroscopy of core levels permit an elementspecific probing of magnetic structure. Examples of this include magnetic $\mathrm{x}$-ray circular dichroism (MXCD) and magnetic $x$-ray linear dichroism (MXLD) in photoelectron emission 1-10 as wéll as MXCD in X-ray absorption 12-15. Because core-level energies tend to be elementallyunique, one is able to specify which element is being interrogated simply by varying the photon and electron energies. The magnetic sensitivity arises because of the construction of a chiral environment, either by the application of circulariy-polarized $x$-rays ${ }^{1-5,10,12-15}$ (i.e., right- or left-handed) or by the imposition of a chiral configuration of vectors, including the poynting and linear polarization vectors of the $x$-rays, the electron emission direction, the crystallographic vectors, and the magnetization vector ${ }^{6-11}$. Here are reported some of the first results of a program in which MXID-photoemission and MXCD-absorption are used to study ultrathin films composed of magnetic alloys of $\mathrm{Co}$ and $\mathrm{Fe}$.

\section{EXPERIMENTAL}

The MXID measurements were performed at the Spectromicroscopy Facility ${ }^{11}$ at the Advanced Light Source in Berkeley, California. The MXCD studies were done at the Stanford Synchrotron Radiation Laboratory (SSRL), using the Beamline 8-2 facilities 1-3,10,14 of the University of California/National Laboratories Participating Research Team. Spectroscopic experimental details are available elsewhere1-3,10,11,14. The FeCo magnetic alloy films were grown on $\mathrm{Cu}(001)$, in situ, using molecular beam epitaxy (MBE) techniques in a UHV environment ${ }^{11,16}$.

1996 Spring Meeting of the Materials Research Sociery Symposium DD: Applications of Synchrotron Radiation 


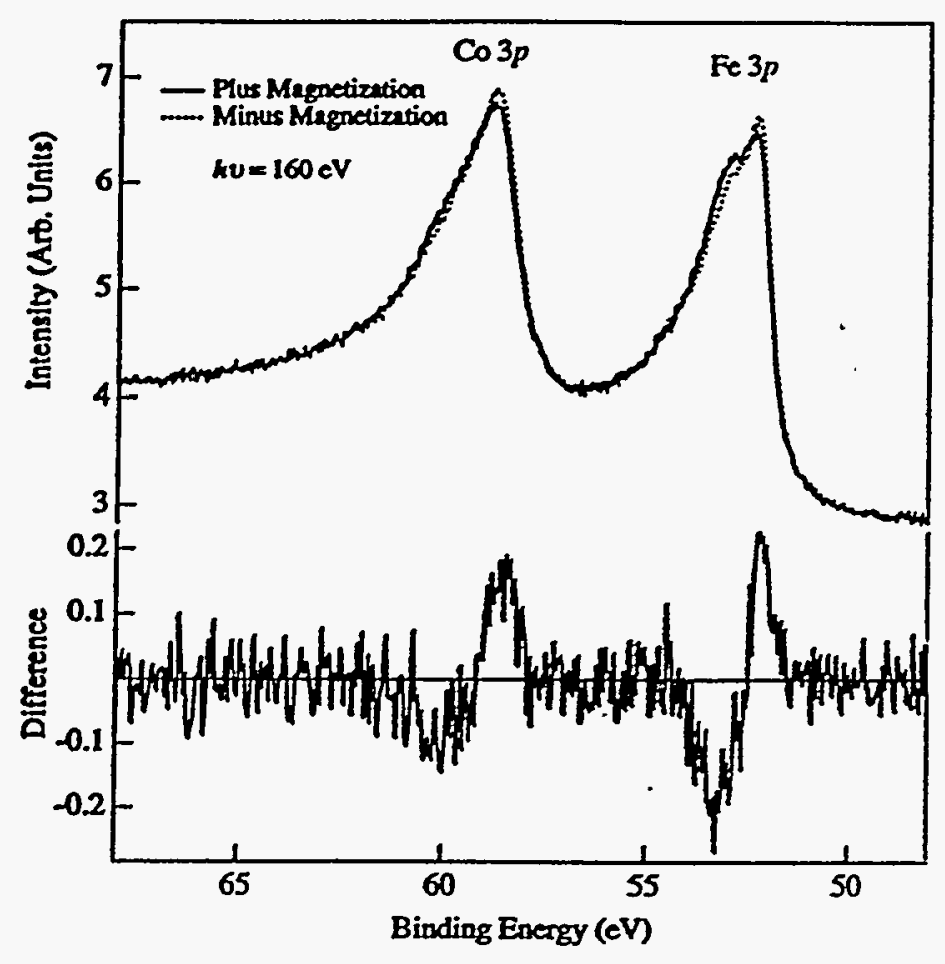

Figure 1. MXID photoelectron spectroscopy of 3.5ML (FeCo2)/Cu(OO1) is shown here. The Fe3p peak is near a binding energy of $53 \mathrm{eV}$ and the Co3p peak near $59 \mathrm{eV}$. To obtain $\mathrm{MXID}$, the magnetization direction is reversed while all else is kept the same. These spectra are for a photon energy of $160 \mathrm{eV}$ and for electrons collected along the surface normal. The asymmetries of $1 \%$ to $2 \%$ are calculated by including the total underlying electron background. If pre-peak regions are set to zero, asymmetries of roughly $3 \%$ are obtained.

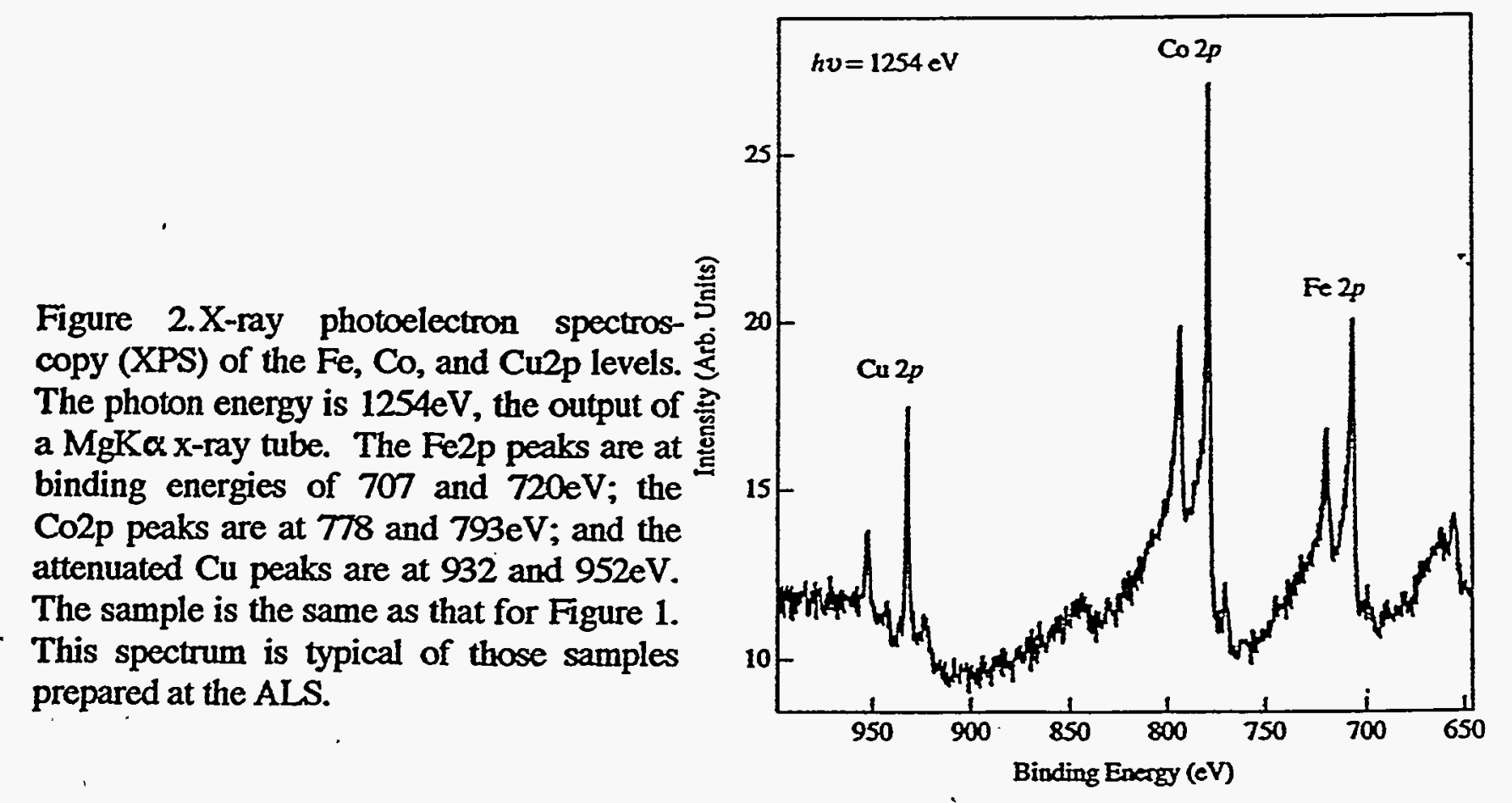

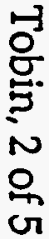




\section{RESULTS AND DISCUSSION}

An example of MXLD-photoelectron emission is shown in Figure 1. Here a dichroism is observable in both the Fe3p and $\mathrm{CO} 3 \mathrm{p}$ peaks. In this photon energy range, the cross-sections are energy-dependent. Intensities require further corrections for utilization in composition analysis. In fact, at low photon energies and these film thicknesses, it is often impossible to get a strong Cu3p substrate peak. Thus, film composition and thickness analysis require another measurement, an example of which is shown in Figure 2. From this, we estimate that the composition of the film is Fe36\%CO64\% and the thickness is 3.5 monolayers of $1.8 \AA$ each. Alternatively, the $3 p$ levels can be used for composition analysis, if a higher photon energy is used. Figure 3 shows a result for a photon energy of $563 \mathrm{eV}$, taken at SSRL. Here the composition is $\mathrm{Fe}_{29 \%} \mathrm{CO}_{71 \%}$, again nominally $\mathrm{FeCO}_{2}$. The coverage is estimated to be 2.4 monolayers. At SSRL, the MXCD-absorption experiments are performed. In Figures 4 and 5 , the absorption spectra of the Fe2p and Co2p levels are shown, respectively. Here MXCD absorption dichroisms are easily seen in both the Fe2p and Co2p levels of this sample, 2.4ML(FeCo2)/Cu(001).

\section{SUMMARY}

Preliminary results have been presented, from our program investigating ultrathin magnetic alloy epitaxial films with MXID-photoemission and MXCD-absorption. We anticipate being able to correlate $M X C D$ and $M X I D$ results for a wide range of samples in the future.

\section{ACKNOWLEDGMENTS}

Work performed under the auspices of the U.S. Department of Energy by the Lawrence Livermore National Laboratory under contract number W-7405-ENG-48. The Spectromicroscopy Facility and the Advanced Light Source were constructed under support from the U.S. Department of Energy. The Advanced Light Source and the Stanford Synchrotron Radiation Laboratory are operated with support from the U.S. Department of Energy.

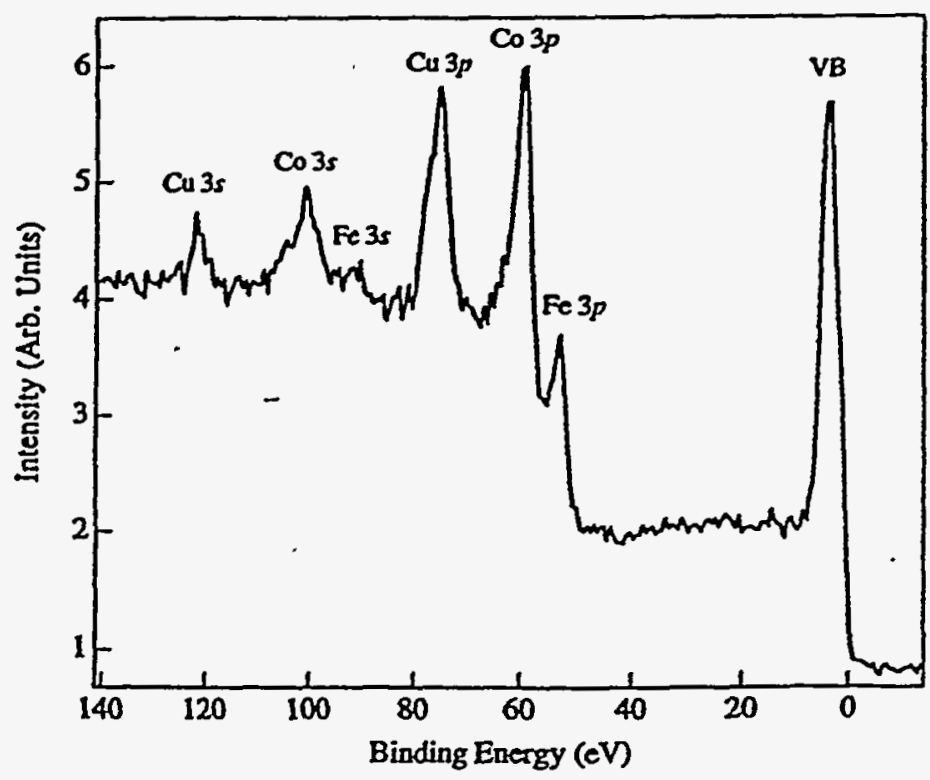

Figure 3. A synchrotron radiation photoelectron spectrum of $\mathrm{FeCO}_{2} / \mathrm{Cu}(0 \mathrm{O} 1)$, prepared at SSRL and excited with photons of $563 \mathrm{eV}$ energy. The valence bands are easily observable near the Fermi energy (binding energy of zero), as are the Fe3p $(53 \mathrm{eV}), \mathrm{Co} 3 \mathrm{p}(59 \mathrm{eV}), \mathrm{Cu} 3 \mathrm{p}(75,7 \mathrm{eV})$, $\mathrm{Fe} 3 \mathrm{~s}(91 \mathrm{eV}), \mathrm{Co} 3 \mathrm{~s}(101 \mathrm{eV})$, and $\mathrm{Cu} 3 \mathrm{~s}$ $(122 \mathrm{eV})$. 


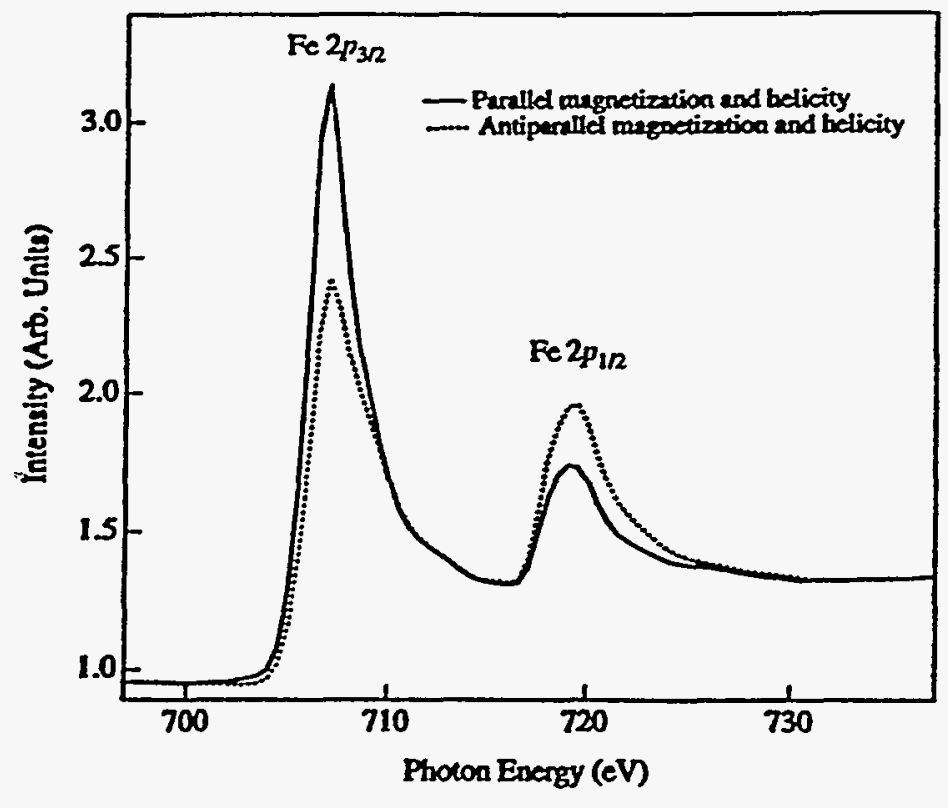

Figure 4. The absorption spectra of the Fe2p3/2 (707eV) and Fe2p $1 / 2(720 \mathrm{eV})$ levels, for parallel and anti-parallel helicity and magnetization. For ease of operation and high counting rate, these measurements were taken with an estimated circular polarization of about $70 \%$ as opposed to the usual values of $85-90 \% 1.14$. Nevertheless, a strong dichroism is easily observed. The sample is the same as that used in Figure 3. Over the $\mathrm{Fe}$ edge region, an interpolated $\mathrm{I}_{\mathrm{O}}$ was used to correct for photon intensity, because of absorption at the Fe edge by part of the $\mathrm{I}_{\mathrm{O}}$ assembly. The interpolated $\mathrm{I}_{\mathrm{O}}$ was obtained by measuring the $\mathrm{I}_{\mathrm{O}}$ spectrum after removing the $F e$ from the $I_{o}$ assembly.

Figure 5. $\mathrm{X}$-ray absorption spectra of $\mathrm{Co}_{2} \mathrm{p}_{3 / 2}(778 \mathrm{eV})$ and Co3p $1 / 2(793 \mathrm{eV})$, same as Figure 4. As in Figure 4, the data has been matched at the pre-peak and postpeak regions.

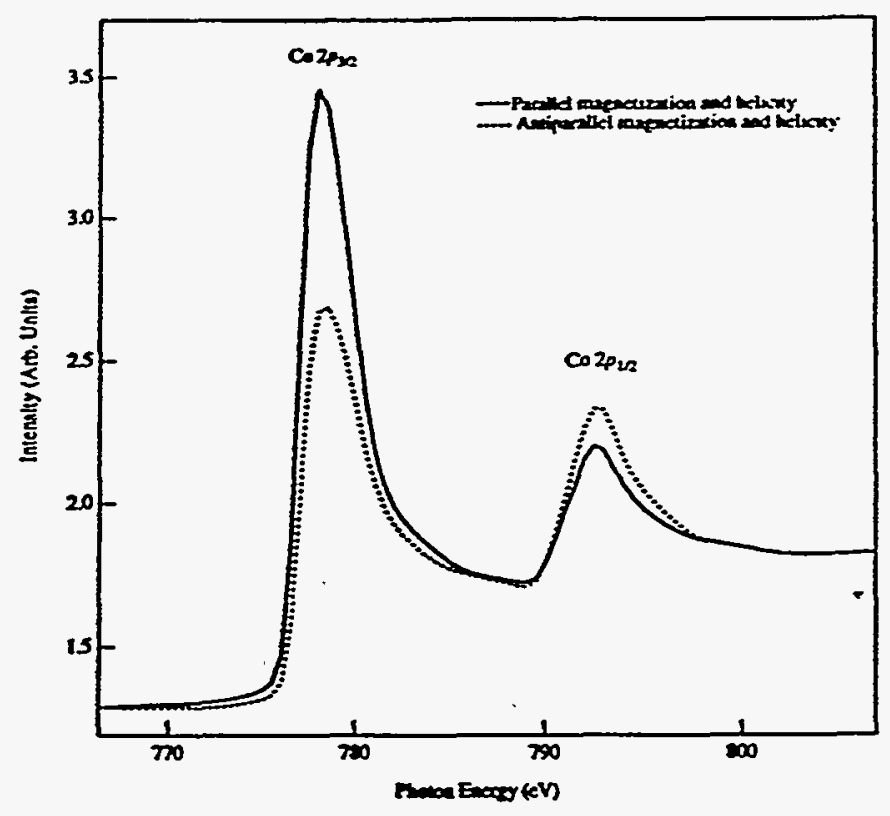




\section{REFERENCES}

1. J.G. Tobin, G.D. Waddill, E. Tamura, P.A. Sterne, P.J. Bedrossian, D.P. Pappas, X. Guo, and S.Y. Tong, Surf. Rev. Lett. XX, XXX (1996).

2. G.D. Waddill, J.G. Tobin, X. Guo, and S.Y. Tong, Phys. Rev. B $\underline{50}$, 6774 (1994).

3. G.D. Waddill, J.G. Tobin, and D.P. Pappas, Phys. Rev. B 46, 552 (1992).

4. K. Starke, L. Baumgarten, E. Arenholz, E. Navas, and G. Kaindl, Phys. Rev. B $\underline{50}, 1317$ (1994).

5. L. Baumgarten, C.M. Schneider, H. Petersen, F. Schafers, and J. Kirschner, Phys. Rev. Lett. 65, 482 (1990).

6. C.H. Roth, F.U. Hillebrecht, H.B. Rose, and E. Kisker, Phys. Rev. Lett. 70, 3479 (1993); Solid State Commun. $\underline{86}, 647$ (1993).

7. G. Rossi, F. Sirotti, N.A. Cherepkov, F. Cambet-Farnoux, and F. Panaccione, Solid State Commun. 90557 (1994); F. Sirotti and G. Rossi, Phys. Rev. B 49, 15682 (1994).

8. W. Kuch, M.T. Lin, W. Steinhogl, C.M. Schneider, D. Venus, and J. Kirschner, Phys. Rev B $\underline{51} 609$ (1995).

9. C.M. Schneider, D. Venus, and J. Kirschner, Phys. Rev. B 45, 5041 (1992).

10. E. Tamura, G.D. Waddill, J.G. Tobin; and P.A. Steme, Phys. Rev. Lett $\underline{63}, 3642$ (1992).

11. J.G. Tobin, K.W. Goodman, G.M-Mankey, R.F. Willis, J.D. Denlinger, E Rotenberg, and A. Warwick, J. Appl. Phys. $\underline{79}$, XXX (1996).

12. G. Schutz, W. Wagner, W. Wilhelm, P. Kienle, R. Zeller, P. Frahm, and G. Materlik, Phys. Rev. Lett. 58, 737 (1987).

13. C.T. Chen, F. Sette, Y. Ma, and S. Modesti, Phys. Rev. B. 42,7262 (1990).

14. J.G. Tobin, G.D. Waddill, and D.P. Pappas, Phys. Rev. Lett $\underline{68}, 3642$ (1992); J.G. Tobin, G.D. Waddill, A.F. Jankowski, P.A. Sterne, and D.P. Pappas, Phys. Rev. B 52, 6530 (1995).

15. J. Stohr, et al., Science, 259, 658 (1993).

16. G.J. Mankey, M.T. Kief, and R.F. Willis, J. Vac. Sci. Technol. A9, 1595 (1991); F. Huang, M.T. Kief, M.J. Mankey, and R.F. Willis, Phys. Rev. B 49, 3962 (1994). 